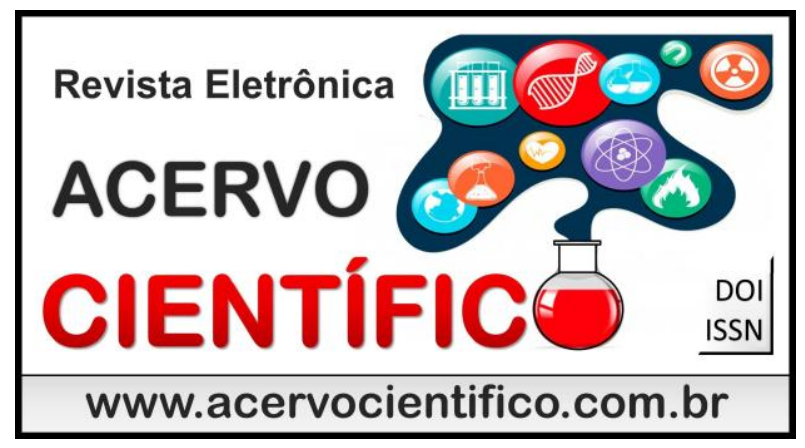

\title{
ORIGINAL
}

Recebido em: 5/2019

Aceito em: 6/2019

Publicado em: 8/2019

\section{Morbimortalidade hospitalar por câncer colorretal no Brasil, no período de 2008 a 2016}

\author{
Hospital morbidity and mortality by colorectal cancer in Brazil from 2008 to 2016
}

\author{
Morbimortalidad hospitalar por cancer colorectal em Brasil en el período de 2008 a 2016
}

Andrey Alves Silva ${ }^{1 *}$, Hiltonn Muniz Cordeiro ${ }^{1}$, Maria Clara Costa Novaes ${ }^{1}$, Mariana Brandão Soares Sousa ${ }^{1}$, Rogério Patrocínio Maria Magalhães ${ }^{1}$, Marcos Vinícius Macedo de Oliveira².

\begin{abstract}
Resumo: O câncer colorretal (CCR) inclui tumores que acometem um segmento do intestino grosso (cólon) e o reto, constituindo uma das principais causas de morbidade e mortalidade em diversos países. O objetivo foi avaliar a morbimortalidade hospitalar por câncer colorretal no período de 2008 a 2016, comparando os índices de internações e mortalidade. O estudo é ecológico, retrospectivo e quantitativo. Foram avaliados pacientes com neoplasia maligna do cólon, junção retossigmoidea, reto, ânus/canal anal, atendidos pela rede de saúde pública entre 2008 e 2016, registrados no Sistema de Informações Hospitalares do Sistema Único de Saúde (SIH/SUS). Analisaram-se dados de faixa etária, sexo, internações, óbitos e taxa de mortalidade. Houve uma média nacional crescente no período analisado, com maior taxa na região Sul. A faixa etária - maior de 60 anos - atingiu mais de $44 \%$ das internações e mais que $62 \%$ dos óbitos. Notificações de óbitos no sexo feminino foram discretamente maiores.
\end{abstract}

Palavras-chave: Câncer Colorretal, Intestino Grosso, Morbimortalidade.

\begin{abstract}
Colorectal cancer (RCC) includes tumors that affect a segment of the large intestine (colon) and rectum, being one of the main causes of morbidity and mortality in several countries. The objective was to evaluate the hospital morbimortality for colorectal cancer from 2008 to 2016, comparing hospitalization rates and mortality. The study is ecological, retrospective and quantitative. Patients with malignant neoplasia of the colon, rectosigmoid junction, rectum, anus / anal canal, attended by the public health network between 2008 and 2016, were registered in the Hospital Information System of the Unified Health System (SIH / SUS). Data on age, sex, admissions, deaths and mortality rate were analyzed. There was a growing national average in the analyzed period, with a higher rate in the South. The age group - over 60 years old - reached more than $44 \%$ of hospitalizations and more than $62 \%$ of deaths. Reports of female deaths were slightly higher.
\end{abstract}

Keywords: Colorectal Cancer, Large Intestine, Morbidity and Mortality.

${ }^{1}$ Centro Universitário FIPMoc (UNIFIPMoc), Montes Claros-MG. *E-mail: andreyy99@hotmail.com

${ }^{2}$ Universidade Estadual de Montes Claros (UNIMONTES), Montes Claros-MG. 
Resumen: El cáncer colorrectal (CCR) incluye tumores que acomete un segmento del intestino grueso (colon) y el recto, constituyendo una de las principales causas de morbilidad y mortalidad en diversos países. El objetivo fue evaluar la morbimortalidad hospitalaria por cáncer colorrectal en el período de 2008 a 2016, comparando los índices de internaciones y mortalidad. El estudio es ecológico, retrospectivo y cuantitativo. Se evaluaron pacientes con neoplasia maligna del colon, unión rectossigmoidea, recto, anus / canal anal, atendidos por la red de salud pública entre 2008 y 2016, registrados en el Sistema de Informaciones Hospitalarias del Sistema Único de Salud (SIH / SUS). Se analizaron datos de grupo de edad, sexo, internaciones, muertes y tasa de mortalidad. Se observó una media nacional creciente en el período analizado, con mayor tasa en la región Sur. El grupo de edad - mayor de 60 años - alcanzó más del $44 \%$ de las internaciones y más del $62 \%$ de las muertes. Las notificaciones de muertes en el sexo femenino fueron discretamente mayores.

Palabras clave: Cáncer Colorrectal, Intestino grueso, La morbilidad y la mortalidad.

\section{INTRODUÇÃO}

Dentre os diversos tipos de câncer, destaca-se o câncer colorretal (CCR), que inclui tumores que acometem um segmento do intestino grosso, o cólon e o reto. Trata-se de uma das principais causas de morbidade e mortalidade em alguns países, como o Brasil, os Estados Unidos e também, nos últimos anos, em alguns países europeus (CREUZ D, 2016).

A carcinogênese colorretal se caracteriza pelo acúmulo de mutações e alterações epigenéticas em diversos genes supressores de tumor, oncogenes e genes associados ao reparo de erros de pareamento do DNA, resultando na transformação celular do epitélio colorretal. Na evolução molecular desse tumor, devese enfatizar o papel central do pólipo adenomatoso como lesão precursora, que propõe mutações nos genes supressores de tumor e oncogenes, em uma ordem específica. O primeiro evento é a inativação do gene APC (Adenomatous polyposis coli), o que leva a um crescimento celular anormal. A mutação do protooncogene K-RAS (Kirstenrat Sarcoma Viral Oncogene homolog) promove a evolução do adenoma. Na etapa seguinte, ocorre a deleção do gene supressor de tumor DCC (Deleted in Colo rectal cancer) e de outros genes localizados próximos a ele, no braço longo do cromossomo 18. A última etapa da progressão para carcinoma é a perda de uma região específica em 17-p, onde se encontra o gene TP-53 (SILVA PPD, 2016; KANTHAN R et al., 2012).

Dentre os fatores de risco para desenvolvimento de CCR, destacam-se os papéis dos fatores genéticos, da dieta e estilo de vida (CHAN AT e GIOVANNUCCI EL, 2010). Geralmente, um maior consumo de frutas e vegetais, que são alimentos ricos em fibras, está associado com risco diminuído da doença. As fibras podem absorver ou diluir substâncias cancerígenas fecais, modular o tempo de trânsito no cólon, reduzir o $\mathrm{pH}$ do cólon ou aumentar a produção de ácidos graxos de cadeia curta. Por outro lado, a ingestão de carnes processadas e carne vermelha estão relacionadas a um aumento do risco para o desenvolvimento do (SILVA PPD, 2016).

Após a instalação da doença, o quadro clínico do câncer de intestino grosso é melhor caracterizado em pessoas com mais de 50 anos, com anemia de origem indeterminada e que apresentam suspeita de perda crônica de sangue no exame de sangue. A perda de peso sem razão aparente, cansaço, fezes pastosas de cor escura, náuseas, vômitos e sensação dolorida na região anal, com esforço ineficaz para evacuar são manifestações comuns. A mudança no hábito intestinal (diarreia ou constipação), desconforto abdominal com gases ou cólicas, sangramento nas fezes, sangramento anal e sensação de que o intestino não se esvaziou após a evacuação são sinais de alerta (SILVA CPD, 2014).

Estudos recentes indicam o uso da pesquisa de sangue oculto nas fezes (PSOF) como rastreio e acompanhamento de pacientes sem fatores de risco para câncer de intestino grosso (CIG) e que esse método realizado anualmente pode diminuir em até $16 \%$ a mortalidade por esse câncer. A PSOF consiste na identificação de hemoglobina nas fezes, podendo ser realizado pelos seguintes métodos: teste da o- 
tolidina (tradicional) e teste imunológico, que detectam especificamente a hemoglobina humana. Os testes imunológicos não necessitam de dieta prévia e são específicos para a hemoglobina humana, sendo considerados na literatura como os de melhor sensibilidade (75\%) e especificidade (40 a 50\%). A PSOF é um método de detecção precoce do CIG, boa alternativa para o rastreamento, no entanto, é necessária a complementação da investigação por meio de exame endoscópico. A colonoscopia exerce papel diagnóstico e terapêutico, sendo considerado o melhor exame preventivo dos cânceres de intestino grosso, em especial o colorretal. Porém, pelo seu alto custo e o fato de ser invasivo, torna-se inviável utilizá-la como método padrão de rastreio (JUNIOR et al., 2015).

O tratamento inicial a ser considerado é o cirúrgico, retirando a parte do intestino afetada e os nódulos linfáticos próximos à região. Em seguida, a radioterapia, associada ou não à quimioterapia é utilizada com o objetivo de diminuir o risco de volta do tumor. O tratamento depende em primeiro momento do tamanho, localização e extensão do tumor. Se a doença está espalhada, com metástases para o fígado, pulmão ou outros órgãos, a possibilidade de cura encontra-se substancialmente reduzida (AMERICAN CANCER SOCIETY, 2008).

Desta forma, o objetivo deste estudo foi avaliar a morbimortalidade pelo câncer colorretal no período de 2008 a 2016, comparando os índices de internações e mortalidade no período analisado. Para isso, foi preciso calcular a taxa de mortalidade por este câncer no Brasil, estimar a ocorrência de internações e óbitos pelo câncer colorretal nas cinco regiões do país e, por fim, descrever as internações e óbitos em relação às informações sobre sexo e faixa etária.

\section{MÉTODOS}

Trata-se de um estudo ecológico, retrospectivo, de abordagem quantitativa. A população a ser investigada no presente estudo representa pacientes com neoplasia maligna do cólon, junção retossigmoidea, reto e ânus ou canal anal, atendidos pela rede de saúde no período de 2008 a 2016 as quais houve o registro no Sistema de Informações Hospitalares do Sistema Único de Saúde (SIH/SUS). As variáveis consideradas, no intuito de elaborar o perfil epidemiológico da população acometida pelo câncer colorretal no Brasil, foram: faixa etária; sexo; internações; óbitos e taxa de mortalidade. Internação e óbitos foram descritos por sexo e faixa etária ao longo de triênios entre 2008 e 2016.

Para os cálculos de taxas de mortalidade por milhão de habitantes, foram utilizados os dados do censo populacional estimado pelo Instituto Brasileiro de Geografia e Estatística (IBGE), disponível no seguinte endereço eletrônico: (http://www.ibge.gov.br). O IBGE figura como uma organização pública responsável pelos levantamentos e gerenciamentos dos dados e estatísticas brasileiras.

Os dados foram coletados através SIH/SUS, durante o primeiro semestre do ano de 2017, disponibilizados pelo Departamento de Informática do Sistema Único de Saúde (DATASUS), pelo seguinte endereço eletrônico: (http://www.datasus.gov.br). O DATASUS consiste em uma medida para a democratização da saúde e o aprimoramento de sua gestão, na qual se realizou a informatização das atividades do Sistema Único de Saúde (SUS), dentro de diretrizes tecnológicas adequadas. O SIH, por sua vez, é um sistema que registra todos os atendimentos provenientes de internações hospitalares pelo SUS.

Os valores observados foram dispostos em gráficos e tabelas permitindo uma melhor análise destes. Foram calculadas prevalências, porcentagens e realizada a organização dos resultados do país em sua totalidade, assim como de cada região. Para o gerenciamento e análise dos dados, foi utilizado o software Excel 14.0 (Office 2010).

\section{RESULTADOS}

O levantamento de dados traz consigo resultados de taxas de mortalidade por milhão de habitantes em cada região do país, por ano e por triênio, além da média nacional. A média nacional da taxa de mortalidade por câncer colorretal foi de, aproximadamente, 16,2 óbitos/1.000.000 habitantes em 2008, 17,6 em 2009; 
19,9 em 2010; 21,5 em 2011; 23,3 em 2012; 24,5 em 2013; 25,7 em 2014; 26,9 em 2015 e 25,3 em 2016. Quanto às médias regionais, nota-se um crescente aumento das taxas de mortalidade nas médias trienais em praticamente todas as regiões do país, assim como na nacional, conforme explicitado na (Tabela 1).

Tabela 1 - Médias trienais da taxa de mortalidade por região e a média nacional geral. Brasil, 2008-2016.

\begin{tabular}{lcccccc}
\hline Período & N & NE & SE & S & CO & Nacional \\
\hline 2008-10 & 6,5 & 7,3 & 24,2 & 26,9 & 16,8 & 17,9 \\
$\mathbf{2 0 1 1 - 1 3}$ & 7,1 & 11,1 & 31 & 34,1 & 19,9 & 23,1 \\
$\mathbf{2 0 1 4 - 1 6}$ & 8,8 & 13 & 34,3 & 40,4 & 19,7 & 26
\end{tabular}

Fonte: IBGE, 2015. Sistema de Informações Hospitalares do SUS (SIH/SUS), 2017.

Legenda: N: Norte; NE: Nordeste; SE: Sudeste; S: Sul; CO: Centro-Oeste.

$\mathrm{Na}$ (Figura 1) pode-se observar esse crescente aumento da taxa de mortalidade anualmente, conforme os resultados evidenciados. Percebe-se que a região Sul é a de maior média de taxa de mortalidade, acompanhada de perto pela região Sudeste, ambas acima da média nacional. Em contrapartida, a região Norte apresenta as menores taxas de mortalidade, e junto com a região Nordeste e Centro-Oeste, ajudam a reduzir a média nacional (MN).

Figura 1 - Curvas de taxas de mortalidade por região e média nacional, no período de 2008 a 2016, por milhão de habitantes.

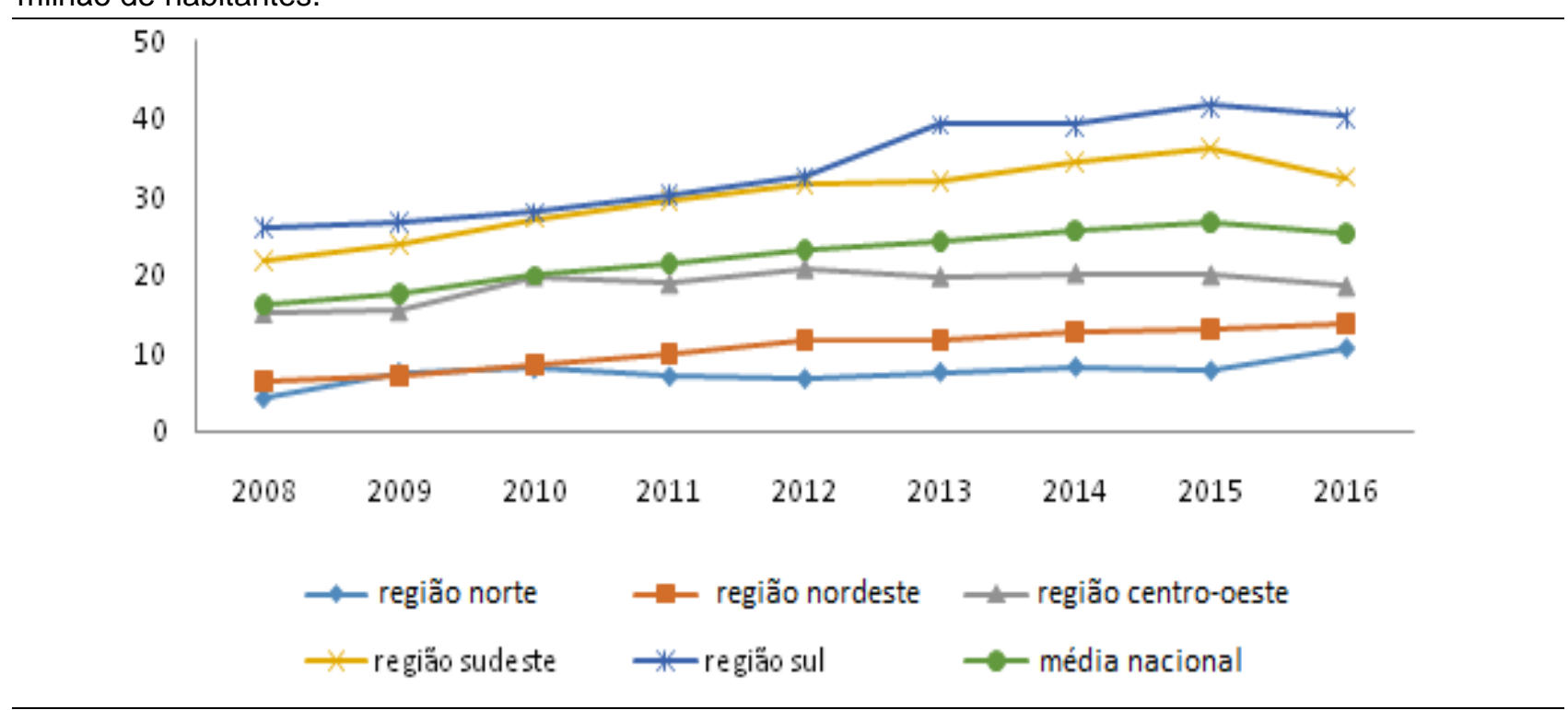

Fonte: IBGE, 2015. Sistema de Informações Hospitalares do SUS (SIH/SUS), 2017.

Nos dados referentes a internações e óbitos de pacientes por neoplasia maligna do cólon, junção retossigmoide, reto, ânus e canal anal, foram encontrados valores semelhantes em relação aos sexos. Destaca-se o aumento de, aproximadamente, 64\% nas internações de indivíduos do sexo masculino e $63 \%$ referente ao sexo feminino quando comparados o primeiro com o terceiro triênios. A despeito dos óbitos, houve um padrão semelhante, porém com discreto predomínio no sexo feminino. O crescimento ao longo dos triênios foi evidenciado em ambos os sexos: $54,18 \%$ nos óbitos femininos e $50,13 \%$ nos óbitos masculinos (Tabela 2). 
Tabela 2 - Internações e óbitos por neoplasia maligna do cólon, junção retossigmoide, reto, ânus e canal anal, por triênios, de acordo com sexo e idade, de 2008 a 2016.

\begin{tabular}{|c|c|c|c|c|c|c|c|}
\hline \multirow[b]{2}{*}{ Variáveis } & \multirow[b]{2}{*}{ Triênios } & \multicolumn{3}{|c|}{ Internações } & \multicolumn{3}{|c|}{ Óbitos } \\
\hline & & $2008-2010$ & 2011-2013 & 2014-2016 & $2008-2010$ & 2011-2013 & 2014-2016 \\
\hline \multirow{3}{*}{ Sexo } & Masculino & $\begin{array}{c}59.703 \\
(49,83 \%)\end{array}$ & $\begin{array}{c}82.493 \\
(50,28 \%)\end{array}$ & $\begin{array}{c}97.997 \\
(50,03 \%)\end{array}$ & $\begin{array}{c}5.068 \\
(48,39 \%)\end{array}$ & $\begin{array}{c}6.533 \\
(48,15 \%)\end{array}$ & $\begin{array}{c}7.814 \\
(49,06 \%)\end{array}$ \\
\hline & & 60.100 & 81.572 & 97.872 & 5.404 & 7.035 & 8.113 \\
\hline & remınıno & $(50,16 \%)$ & $(49,71 \%)$ & $(49,96 \%)$ & $(51,60 \%)$ & $(51,84 \%)$ & $(50,93 \%)$ \\
\hline \multirow{3}{*}{ Idade } & Abaixo de 30 anos & $\begin{array}{c}14.417 \\
(12.03 \%)\end{array}$ & $\begin{array}{c}9.062 \\
(5,51 \%)\end{array}$ & $\begin{array}{c}6.794 \\
(3,46 \%)\end{array}$ & $\begin{array}{c}288 \\
(2,75 \%)\end{array}$ & $\begin{array}{c}238 \\
(1,74 \%)\end{array}$ & $\begin{array}{c}730 \\
(1,27 \%)\end{array}$ \\
\hline & Entre 30 e 59 anos & $\begin{array}{c}52.330 \\
(43,68 \%)\end{array}$ & $\begin{array}{c}73.854 \\
(45,01 \%)\end{array}$ & $\begin{array}{c}86.451 \\
(44,13 \%)\end{array}$ & $\begin{array}{c}3.677 \\
(35,11 \%)\end{array}$ & $\begin{array}{c}5.138 \\
(35,10 \%)\end{array}$ & $\begin{array}{c}13.718 \\
(33,13 \%)\end{array}$ \\
\hline & Mais de 60 anos & $\begin{array}{c}53.056 \\
(44,28 \%)\end{array}$ & $\begin{array}{c}81.149 \\
(49,46 \%)\end{array}$ & $\begin{array}{c}102.624 \\
(52,39 \%)\end{array}$ & $\begin{array}{c}6.507 \\
(62,13 \%)\end{array}$ & $\begin{array}{c}8.567 \\
(63,14 \%)\end{array}$ & $\begin{array}{c}25.519 \\
(65,58 \%)\end{array}$ \\
\hline
\end{tabular}

Fonte: Sistema de Informações Hospitalares do SUS (SIH/SUS), 2017.

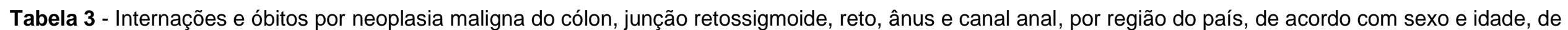
2008 a 2016.

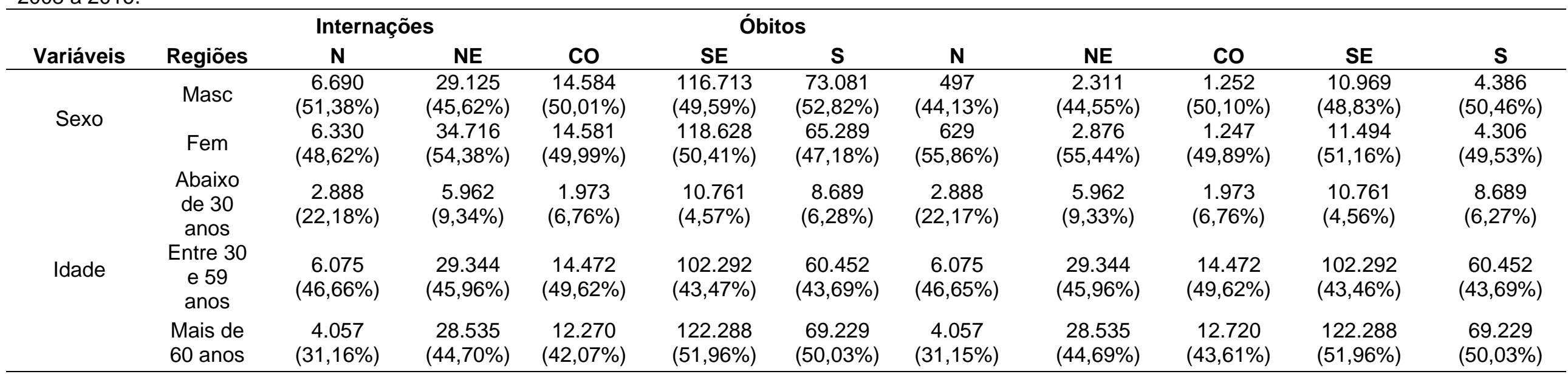

Fonte: Sistema de Informações Hospitalares do SUS (SIH/SUS), 2017.

Legenda: N: Norte; NE: Nordeste; CO: Centro-Oeste; SE: Sudeste; S: Sul. 
De acordo com os dados obtidos relativos à idade dos pacientes internados e falecidos, houve um destaque considerável para os pacientes acima de 60 anos, que protagonizaram a maioria das notificações dos três triênios analisados. Neste sentido, esta faixa etária atingiu mais de $44 \%$ das internações e mais que $62 \%$ dos óbitos durante os anos de 2008 a 2016. Em contrapartida, a faixa etária inferior a 30 anos representa a menor parcela de internações e falecimentos, responsável por uma média de $7 \%$ das internações e 1,92\% dos óbitos ocorridos durante os nove anos analisados neste trabalho (Tabela 2).

Os valores encontrados para internações de acordo com sexo foram próximos percentualmente, tendo a maior variação na região Nordeste, apresentando $8,8 \%$ de mulheres a mais que os homens. Em relação ao número de óbitos, observou-se maior variação entre os sexos, nas regiões Norte e Nordeste, $11,2 \%$ e 10,8\% de mulheres a mais, respectivamente (Tabela 3).

$\mathrm{Na}$ avaliação por faixa etária, quanto às internações, a variação significativa para indivíduos idade inferior a 30 anos foi na região Norte, com 22,18\% (2.888 internações), enquanto as demais regiões não passaram dos $10 \%$ nessa faixa etária. Consequentemente, o Norte obteve menor número de casos na população acima de 60 anos $31,16 \%$ (4.057) uma vez que todas as regiões apresentaram percentual de internação semelhante para indivíduos de 30 a 59 anos. Avaliando-se os óbitos para menores de 30 anos, a região Norte apresentou novamente o maior valor, 22,17\% (2.888 casos). Nos maiores de 60 anos, o Sudeste foi responsável pelo maior número de falecimentos (51,96\%), já o Norte, o menor (31,15\%). Entre 30 e 59 anos, todas as regiões do país apresentaram resultados semelhantes entre si (Tabela 3)

\section{DISCUSSÃO}

Grande parte dos estudos estatísticos epidemiológicos adota o termo câncer colorretal (CCR) como aquele que acomete o cólon, a junção retossigmoide, o reto, o ânus e o canal retal (códigos C-18, C-19, C20 e C-21 da Classificação Internacional de Doenças - CID 10), independentemente das divergências ao se classificar epidemiologicamente as neoplasias de canal anal e ânus (FACINA TE, 2011). Apesar do $\mathrm{SIH} / \mathrm{SUS}$ não adotar tal nomenclatura englobando todos os tumores supracitados, será utilizado o termo CCR no presente estudo por esta ser uma nomenclatura difundida no âmbito nacional e adotada pelo Instituto Nacional do Câncer (INCA).

De modo geral, vários autores relatam ligeiro predomínio do sexo masculino quanto ao número de casos por CCR, o que diverge dos resultados encontrados no presente estudo (FACINA TE, 2011). O sexo feminino (tabela 2) foi o mais acometido nas regiões Norte $(55,86 \%)$, Nordeste $(55,44 \%)$ e Sudeste $(51,16 \%)$, assim como em fontes analisadas, não havendo, portanto, um sexo universalmente mais acometido (DE MENEZES CCS, et al., 2016). É comum a alguns autores o relato de maior sobrevida em 5 a 10 anos do sexo feminino, fato geralmente atribuído a questões hormonais. A reposição estroprogestativa através da terapia de reposição hormonal reduz o risco do CCR, entretanto, o mecanismo de ação ainda permanece desconhecido. Supõe-se que os progestágenos atuam reduzindo a proliferação celular colônica. Já o estrogênio, interfere reduzindo a concentração de ácidos biliares, os quais podem estar relacionados ao desenvolvimento de alterações malignas no cólon (ROZENBERG S, et al., 2013).

A mortalidade causada pelo CCR é elevada, sendo a sobrevida média em cinco anos de $40 \%$ em países em desenvolvimento e 55\% em países com índice de desenvolvimento (IDH) elevado (FACINA TE, 2011). O número de óbitos encontra-se em ascensão no Brasil na última década, no entanto, não se sabe se isso ocorre pelo maior número de notificações e acurácia no sistema de notificação ou se, de fato, há um aumento das taxas de mortalidade no país (DE MENEZES CCS, et al., 2016). Observa-se que há um predomínio de algumas regiões sobre outras. No presente trabalho, as regiões Sul e Sudeste apresentaram as maiores taxas de mortalidade no país, o contrário das regiões Norte e Nordeste, que tiveram as menores taxas. Isso pode ser justificado pela maior ocorrência de fatores de risco naquelas em relação a estas. Dentre esses fatores, podem-se citar os hábitos de vida modificáveis, que têm estreita relação com o desenvolvimento de doenças crônicas não transmissíveis, tais como o CCR (SANTOS LGD, 2015). Neste grupo, estão incluídos o sedentarismo, o tabagismo, a ingestão de álcool e a dieta com elevado teor calórico 
e proteico (SANTOS FP, 2014). De acordo com referências analisadas, cerca de $70,5 \%$ dos casos de CCR poderiam ser evitados com a prática de atividade física regular associada a uma dieta balanceada (VASQUES ALR e PERES MA, 2010).

Neste estudo, a faixa etária de maior acometimento - mais de 60 anos - foi comum a todas as regiões do país. De acordo com a literatura utilizada, o CCR é mais expressivo naqueles com idade além dos 50 anos, acometendo menos de $10 \%$ da população abaixo de tal faixa etária (GOMES CIMR, et al., 2013).

O crescimento da população idosa é um fenômeno mundial. No Brasil, a relação de idosos aumentou de 9,1\% em 1999 para $11,7 \%$ em 2015 e novas projeções indicam que, em 2020, o Brasil será o sexto país do mundo em número de idosos (SOUZA MC, 2012).

Em consequência disso, as doenças relacionadas à idade, como o CCR, terão índices de ocorrência mais significativos. Além disso, o aumento observado entre 2008 e 2016, nos números de internações pode estar associado a outros fatores ligados a essa patologia, não só a idade maior que 50 anos, mas também o fato de morar em regiões com maior desenvolvimento econômico/industrial e social. Observa-se que o CCR afeta principalmente a população dos países desenvolvidos, dado que sugere um risco adicional de até $6 \%$ de ocorrência dessa doença em populações dos grandes centros ocidentais (DOS SANTOS TP, et al., 2013).

No Brasil, a cobertura do Sistema de Informações Hospitalares (SIH) e a qualidade da informação sobre internações que alimentam o sistema variam conforme as diferentes regiões brasileiras (ANDRADE MTSD e TIMENTESKY MDCST, 2009). Os dados podem ser superestimados ou subestimados de acordo com as limitações quantitativas (sub-registro e deficiências no fluxo das declarações) e limitações qualitativas (informações incorretas e erros no processamento de codificação dos dados). Entretanto, na realização desse e outros estudos, pressupõe-se que as limitações qualitativas sejam minimizadas em função da natureza evolutiva da doença, a qual exige um tratamento hospitalar prolongado e exames complementares elucidativos (NEVES FJD, et al., 2006).

No presente estudo, as regiões Sudeste e Sul obtiveram os maiores índices de óbitos por CCR e, as regiões Norte e Centro-Oeste, os menores índices. Considerando que a população de países com elevado IDH está mais propensa a desenvolver o CCR e que as regiões Sudeste e Sul contam com melhor infraestrutura e recursos tecnológicos superiores às demais regiões, os índices elevados de óbitos podem estar relacionados a fatores de risco comuns aos países desenvolvidos (SANTOS TP, et al., 2013; MENEZES CCS, et al., 2016). Os hábitos de vida contemporâneos regidos pelas diferenças geográficas, associados a uma susceptibilidade genética também são um fator de risco adicional a essa população.

De acordo com pesquisa nacional de saúde divulgada pelo IBGE (2014), a região Sul é a segunda menor região do país em termos de consumo proporcional de hortaliças e frutas. É ainda a região com maior percentual de indivíduos maiores de 18 anos de idade consumidores de álcool (28,4\%), tabaco e derivados (16,1\%) e tem um percentual significativo de indivíduos insuficientemente ativos (IBGE, 2014).

Ainda seguindo esta linha de raciocínio, as crianças e adolescentes desta região ingerem, em maioria, carnes vermelhas e embutidos em relação aos outros tipos de carne (ASSUNÇÃO MCF, et al., 2012). Logo, faz-se uma clara associação dos fatores de risco com a maior mortalidade e internações na região sul, porém, sabe-se que o CCR não tem apenas fatores ambientais, mas também um caráter genético muito forte.

Ao realizar uma análise deste estudo, é possível observar que apresenta limitação relacionada à base de dados utilizada, uma vez que está passível de erros de registro e subnotificações. No entanto, os autores acreditam que, por se tratarem de dados nacionais de preenchimento obrigatório pelos serviços de saúde, são informações fidedignas e de importância fundamental para o desenvolvimento de pesquisas científicas.

Dentre essas, destacam-se o aumento crescente da taxa de mortalidade por CCR no período de 2008 a 2015, aumento no número de óbitos de acordo com os triênios analisados, além dos indivíduos acima de 60 anos representarem a população com maior número de óbitos. 
Por fim, sabe-se que o CCR apresenta bom prognóstico e concede maior expectativa de vida ao paciente se diagnosticado e tratado precocemente. Para isso, é imprescindível que profissionais da área de saúde adotem uma postura ativa, recomendando a realização do rastreamento de forma adequada, que auxiliará no diagnóstico da doença em seu estágio inicial. Além desta postura, a disseminação das informações acerca desta neoplasia maligna para a população é essencial, uma vez que, além de destacar a importância do seu diagnóstico precoce, favorecerá a adesão dos pacientes ao screening e a um futuro tratamento, se necessário.

\section{CONCLUSÃO}

Houve um crescente aumento na taxa de mortalidade por CCR no Brasil, no período de 2008 a 2016 tanto no que diz respeito à média nacional quanto regional. A região Sul apresentou a maior taxa, sendo, inclusive, maior que a média nacional. Houve uma ligeira maioria de notificações de óbito pelo sexo feminino e um número consideravelmente maior em maiores de 60 anos. Quanto às internações, a predominância feminina se repetiu, tendo uma variação maior na região norte. Da mesma forma, a faixa etária de maiores de 60 anos prevaleceu. Por outro lado, na análise das regiões, houve um maior número de internações na região sudeste. Tais números reforçaram a preponderância dos fatores ambientais para a patologia em questão

\section{REFERÊNCIAS}

1. CREUZ D, et al. Análise comparativa das indicações e achados colonoscópicos em pacientes menores e maiores de 50 anos. Arquivos Catarinenses de Medicina, 2016.

2. SILVA PPD. Análise de polimorfismos dos genes KIR e HLA classe I em pacientes com câncer colorretal. Porto Alegre. Universidade Federal do Rio Grande do Sul, (2016).

3. KANTHAN R., et al. Molecular events in primary and metastatic colorectal carcinoma: a review. Pathology Research International, 2012.

4. CHAN AT, GIOVANNUCCI EL. Primary prevention of colorectal cancer. Gastroenterology, 2010. 138(6), 20292043.

5. SILVA CPD, et al. A importância da alimentação na prevenção do câncer colorretal. Recife. Revista De Trabalhos Acadêmicos-Universo, 2014. 1(1).

6. JUNIOR JBC, et al. Rastreamento do câncer colorretal no município de Água Doce. Santa Catarina. Anais de Medicina, 2015.

7. AMERICAN CANCER SOCIETY. Colorectal cancer facts \& figures 2008-2010. Atlanta GA, 2008.

8. FACINA TE. A incidência de câncer no Brasil. Rev. bras. cancerologia, 2011. 57(4), 557.

9. MENEZES CCS, et al. Câncer colorretal na população brasileira: taxa de mortalidade no período de 2005 2015. Rev. bras. em promoção da saúde, 2016. 29(2).

10. ROZENBERG S, et al. Postmenopausal hormone therapy: risks and benefits. Nature Reviews Endocrinology, 2013. 9(4), 216-227.

11. SANTOS LGD. Consumo frequente de carne vermelha e processada e sua associação com o desenvolvimento de doenças crônicas não transmissíveis: uma análise a partir da saúde coletiva. Ceilândia. Universidade de Brasília, 2015.

12. SANTOS FP. Ministério Da Saúde. Secretaria De Atenção À Saúde Portaria № 958, 2014.

13. VASQUES ALR, PERES MA. Tendência temporal da mortalidade por câncer de cólon e reto em Santa Catarina no período entre 1980 a 2006. Epidemiologia e Serviços de Saúde, 2010. 19(2), 91-100.

14. GOMES CIMR, et al. Estudo sobre a acurácia da colonoscopia na detecção do câncer colorretal. Rev. Med. Minas Gerais, 2013. 23(3): 307-310.

15. SOUZA MC. O envelhecimento da população brasileira e os desafios para o setor saúde. Cad. saúde pública, 2012. 28(2), 208-209.

16. SANTOS TP, et al. Conhecimento dos usuários do serviço público de saúde sobre câncer colorretal e sua prevenção. Revista da AMRIGS, 2013. 57(1), 31-38.

17. ANDRADE MTSD, TIMENTESKY MDCST. Formação de docentes nos serviços de saúde no Estado de São Paulo. Boletim Epidemiológico Paulista (Online), 2009. 6(68), 24-24.

18. NEVES FJD. Mortalidade por câncer de cólon e reto e consumo alimentar em capitais brasileiras selecionadas. Rev. bras. epidemiologia, 2006. 9(1), 112-120.

19. INSTITUTO BRASILEIRO DE GEOGRAFIA E ESTATÍSTICA (IBGE). Pesquisa Nacional de Saúde 2013: percepção do estado de saúde, estilos de vida e doenças crônicas, 2014.

20. ASSUNÇÃO MCF, et al. Consumo de carnes por adolescentes do Sul do Brasil. Rev. de nutrição, 2012. 25(4): 463-472.

REAC/EJSC | Vol. 5 | e939 | DOI: https://doi.org/10.25248/reac.e939.2019 